\title{
Retraction Note to: Artificial neural networks application to predict the compressive damage of lightweight geopolymer
}

\author{
Ali Nazari ${ }^{1}$ \\ Published online: 10 February 2021 \\ (C) Springer-Verlag London Ltd., part of Springer Nature 2021

\section{Retraction Note: Neural Comput \& Applic (2013) 23:507-518} \\ https://doi.org/10.1007/s00521-012-0945-y
}

The Editor-in-Chief has retracted this article [1] because it significantly overlaps with a large number of articles that were under consideration at the same time, including [2,3], and previously published articles, including [4-6]. Additionally, the article shows evidence of peer review manipulation. The authors have not responded to any correspondence regarding this retraction.

\section{References}

1. Nazari A (2013) Artificial neural networks application to predict the compressive damage of lightweight geopolymer. Neural Comput Applic 23:507-518. https://doi.org/10.1007/s00521-0120945-y
2. Nazari A (2013) RETRACTED ARTICLE: Fuzzy logic-based prediction of compressive strength of lightweight geopolymers. Neural Comput Applic 23:865-872. https://doi.org/10.1007/ s00521-012-1009-z

3. Nazari A, Khalaj G (2012) Prediction compressive strength of lightweight geopolymers by ANFIS. Ceram Int 38(6):4501-4510. https://doi.org/10.1016/j.ceramint.2012.02.026

4. Nazari A (2013) RETRACTED ARTICLE: Artificial neural networks for prediction compressive strength of geopolymers with seeded waste ashes. Neural Comput Applic 23:391-402. https:// doi.org/10.1007/s00521-012-0931-4

5. Nazari A (2013) RETRACTED ARTICLE: Utilizing ANFIS for prediction water absorption of lightweight geopolymers produced from waste materials. Neural Comput Applic 23:417-427. https:// doi.org/10.1007/s00521-012-0934-1

6. Nazari A, Riahi S (2013) RETRACTED ARTICLE: Artificial neural networks to prediction total specific pore volume of geopolymers produced from waste ashes. Neural Comput Applic 22:719-729. https://doi.org/10.1007/s00521-011-0760-х

Publisher's Note Springer Nature remains neutral with regard to jurisdictional claims in published maps and institutional affiliations.
The original article can be found online at https:// doi.org/10.1007/s00521-012-0945-y.

\section{Ali Nazari}

alinazari84@aut.ac.ir

1 Department of Materials Science and Engineering, Saveh Branch, Islamic Azad University, Saveh, Iran 